\title{
Reflexos da intervenção nas áreas centrais das cidades - uma postura crítica frente aos espaços urbanos contemporâneos
}

\author{
Reginaldo Magalhães de Almeida \\ Centro Universitário Uni-BH \\ malmeida@brfree.com.br
}

Resumo: A intervenção nas áreas centrais das cidades, sejam históricas ou não, é um assunto atual nas temáticas que envolvem a questão urbana. Primeiramente, pretendese neste texto analisar os principais pressupostos ligados às intervenções, desde os modelos funcionalistas - meados do século XX - até o pensamento pós-moderno. Posteriormente, desenvolve-se uma avaliação de uma seleção de intervenções consideradas paradigmas contemporâneos: no Brasil o Pelourinho em Salvador e o Rio-cidade no Rio de Janeiro; no exterior a cidade de Barcelona. Ao final, a conclusão discorre sobre os reflexos da reabilitação urbana, considerando, dentre outros, os processos de gentrificação e a transformação da cultura em mercadoria

Palavras-chave: Intervenção urbana, reabilitação, gentrificação, centros urbanos.

Abstract: Downtown intervention, be they in historical cities or not, are important. This papes analyses the main assumptions of interventions, since the funcionalist models - XX - up to the post-modern thinking. Then it analyses two brazilian paradigms: Pelourinho in Salvador and Riocidade in Rio de Janeiro; In Europe, the city of Barcelona. It analyses urban rehabilitation such as cultural transformation.

Key-Words: urban intervention, rehabilitation, urban centers.

\section{Introdução}

Nas discussões sobre a gestão das cidades contemporâneas, um tema é constantemente referido: as intervenções urbanas em suas áreas centrais. No Brasil, são exemplos paradigmáticos dessas intervenções o centro histórico da cidade de Salvador denominado Pelourinho, e o Rio-Cidade da cidade do Rio Janeiro; no exterior, como o projeto mais proeminente, pode-se considerar a cidade de Barcelona. Em todas essas intervenções, deu-se um enfoque grande para as operações urbanas de caráter físico-espacial.

Verifica-se que as propostas de intervenção urbana nas grandes cidades passam a adotar 
cada vez mais uma forma pontual, muito diferente do desejo de planificação total, preconizada nas décadas passadas pelos modernistas. Le Corbusier, arquiteto suíço e principal mentor intelectual dos projetos de planificação total, defendeu no início do século passado, no "Plano Voisin" para Paris, a demolição de áreas urbanas tradicionais, substituindo-as pelo protótipo por ele idealizado - grandes artérias e edifícios verticalizados [1].

Os modernistas propugnavam o rompimento radical com o passado, considerando que a revolução industrial e os fatos que a geraram representavam um decisivo ponto de inflexão na história da humanidade. Deste modo, não fazia sentido que se preservassem formas antigas de cidade, consideradas como anacrônicas em relação às necessidades e possibilidades da era industrial. Dentro da visão funcionalista, a cidade, como lugar de realização e concentração de pessoas e atividades, apresentava, entre outros aspectos negativos, desordem e irracionalidade na distribuição espacial de suas funções sociais básicas, elevadas densidades de ocupação do solo, inadequação e obsolescência no seu sistema de circulação, pouca higiene e insalubridade, carência de espaços livres e áreas verdes, bem como degradação estética generalizada.

Atualmente, abandonando tal visão funcionalista, considera-se que os processos de intervenção são antes de tudo uma estratégia de gestão urbana que procura requalificar o espaço urbano de maneira a valorizar as potencialidades sociais, econômicas e funcionais, através de intervenções múltiplas - urbanísticas, sociais e econômicas, muito distante dos projetos de planificação total.

Porém, verifica-se nas praticas contemporâneas de intervenção urbana alguns reflexos que vem recebendo muitas críticas. Primeiro, os efeitos de um forte processo de gentrificação com projetos voltados para o turismo e para o consumo de uma classe média local. Segundo, o grande incentivo de investimentos públicos e privados com o objetivo principal de ampliar o mercado turístico, voltado para o ócio, como o lazer e o entretenimento, com bares e restaurantes. Terceiro, a mercantilização dos espaços culturais, transformando-os em mercadorias a serem apresentadas como ancoras do processo de atração de turistas ou de marketing com o objetivo da inserção da cidade no cenário mundial. 


\section{Pressupostos das intervenções urbanas}

As grandes propostas de renovação urbana, nas cidades da cultura ocidental, vem ocorrendo desde o Século XVI, iniciando-se com o plano desenvolvido por Sisto V, em Roma, que abriu um rol de experiências, cujo ponto de confluência é a tentativa de imprimir organicidade a um tecido urbano fragmentado da cidade, utilizando um traçado para o sistema viário, baseado em eixos e em praças como diretrizes de projeto.

Contudo, no Século XIX, dois projetos tornaram-se notórios pela sua tentativa de regenerar áreas insalubres das cidades em crescimento: o de Hausmann, em Paris, e o de Ildefonso Cerdá, em Barcelona. O primeiro procurou, por meio de um projeto totalizador, eliminar a insalubridade e a degradação dos bairros centrais de Paris, abrindo grandes avenidas, com largos passeios, criando espaços arborizados, além de revalorizar os principais monumentos da cidade. Já Cerdá estabelece, para Barcelona, um plano com tipologias rígidas de ocupação, seguindo a grelha ortogonal, ruas com $20 \mathrm{~m}$ de largura e diagonais que se cruzam em praças e quarteirões de $113 \mathrm{~m}$ de comprimento, com ocupação lindeira à rua, liberando as áreas internas das quadras para uso público [2].

O início do século XX foi importante para o pensamento relativo às intervenções. Camillo Sitte introduzirá uma orientação, baseada nos princípios compositivos e arquitetônicos medievais. Seguirá as lições da história, recusando a tradição haussmanniana do alinhamento retilíneo, propondo em contrapartida seqüências construídas organizadas de modo orgânico, assimétrico e variado, aproveitando as particularidades do terreno, como era característico no período medieval [3].

O período anterior também é marcado pela forte atividade de construção, expansão das cidades e transformações demográficas e sociais. ao nível institucional, pela criação dos corpos legais que regulamentaram a gestão das cidades, criando pela primeira vez a obrigação de planos.

No Brasil, iniciava-se o processo de êxodo rural e um incipiente desenvolvimento industrial, que mais tarde iriam contribuir para o processo de urbanização do país. A metodologia de projeto de intervenção urbana, adotada na década de 20, utilizará como síntese da resposta aos problemas urbanos e como comunicação de uma 
imagem, a idéia do saneamento e do embelezamento das cidades. Importante é que "as questões continuaram integradas num entendimento morfológico da cidade que atinge grande complexidade e elaboração, já não apenas em ordem a efeitos cênicos, visuais e físicos, mas também sociológicos, funcionais e estruturais" [4]. Foram, de maneira geral, realizações e propostas continuadoras da cidade tradicional. Desde modo cidades como o Rio de Janeiro e São Paulo passaram por grandes transformações.

Após a $2^{\circ}$ guerra mundial, até os anos 70 , na Europa, a reconstrução das cidades e as tremendas necessidades habitacionais (industrialização e fenômenos socais) recorrerão às habitações, aos bairros, às novas cidades, reconstrução dos centros urbanos destruídos em quantidades e ritmos nunca antes conhecidos. Tais intervenções encontravam respaldo então na recusa à cidade tradicional, nas suas formas e na sua configuração, e a procura de novos modelos de organização do espaço urbano, que atendiam a rápida necessidade de construção e de modernização. Deste modo " a lógica do funcionalismo, não sendo nenhuma novidade (desde Vitruvio que existem preocupações funcionalistas), vai exercer grande influência na arquitetura e urbanística modernas". [5]. A pratica adotada será a do progresso, da eficiência, da velocidade, princípios da cidade modernista, que também foram adotados no Brasil.

Enquanto a cidade pré-industrial barroca ordenava os valores do público e de privado, justapondo convenções arquitetônicas de repetição e de exceção, a cidade modernista é concebida como a antítese tanto desse modo de representação, quanto da ordem política que este pretende representar. Postulando a primazia do espaço aberto, da clareza volumétrica, da forma pura e da abstração geométrica, o modernismo dá origem a um novo vocabulário formal, que sem dúvida refletirá nas intervenções urbanas. Desse modo os poderes públicos aderirão, a partir dos anos cinqüenta, à urbanística moderna, oficializando-a e institucionalizando-a até a banalização.

Para a Professora Otília Arantes, "assim, a forma das grandes metrópoles - onde as praças se transformam em simples pontos de passagem e as ruas, lugares suportes de fluxo de circulação para conjuntos verticais constitui, a ilustração mais eloqüente das relações entre o público e privado”. [6]. A melhor demonstração do esvaziamento recíproco do público e do privado está na e-xacta Belo Horizonte
ISSN 1984-3151 www.unibh.br/revistas/exacta

v. 2, n. 1, jun 2009 
arquitetura dos caixotes de vidro que consagram a morte dos dois lados, bem como na abolição da fronteira entre ambos.

Outro efeito ou sintoma é a crescente indiferenciação dos espaços, a ponto de não mais distinguir a residência do escritório, o âmbito doméstico da casa e a circulação de mercadorias.

A estética, a arte urbana e o desenho vão tendo pouco valor face aos graves e sérios problemas demográficos, e sociais. Assim, as intervenções, conduziram o ordenamento territorial, destruindo a forma urbana. Parte cidade ficou funcionalmente resolvida, mas sem espaços identificáveis e significantes da cidade tradicional.

Porém, as primeiras reações contra a urbanística moderna surgem na década de 60. A imagem da cidade reaparece no debate como objetivo determinante para o bem-estar intelectual e social dos cidadãos. A cidade antiga deixa de ser encarada como um território insalubre, mero campo de renovação urbana e imobiliária, passando a ser um bem precioso, insubstituível e de grande valor.

A ativista americana Jane Jacobs tenta demonstrar que a construção das cidades está baseada sobre dados políticos e abstratos, não demonstráveis e cuja aplicação, traduzida pela supressão dos espaços tradicionais, bordejada de habitações, lojas, bares e restaurantes, produz nefastas conseqüências para os habitantes [7]. Tais espaços, revestidos dessas qualidades, seriam o lugar primordial para os contatos sociais quotidianos. $\mathrm{O}$ urbano como lugar do encontro, da simultaneidade, como "teatro espontâneo", é também reabilitado por Henri Lefébvre em "O Direito à Cidade", escrito em 1967. Por teatro espontâneo entende-se o movimento, o imprevisto, o possível e os encontros.

Liderados por Jane Jacobs, envolvendo artistas e intelectuais, surge, um movimento de cunho comunitário, no bairro de Greenwich Village, em Nova Iorque. O movimento se opunha, a demolição de áreas tradicionais para a construção de vias expressas dentro das cidades americanas. $\mathrm{O}$ Programa foi conhecido como "Renovação Urbana" (Urban Renewal) e contava com fundos federais. $\mathrm{O}$ pensamento de intervenção era dominado pela idéia modernista de atender a circulação a qualquer custo. A atuação marcante de alguns intelectuais conseguiu reverter $\mathrm{o}$ poderoso programa federal e restabelecer o equilíbrio entre o benefício de preservar comunidades urbanas e seus bairros, e a e-xacta Belo Horizonte
ISSN 1984-3151 www.unibh.br/revistas/exacta

v. 2, n. 1, jun 20B 9 
realização de programa de obras publicas de escala metropolitana. Jane Jacobs, argumentava que a higiene física - grandes artérias e conjuntos habitacionais - não significa higiene mental, as cidades necessitam de prédios antigos, (não se referindo aqui a monumentos históricos tombados) como a precondição para que os bairros sejam mais eficientes e seguros.

A modificação e a destruição do tecido urbano tradicional, transformava radicalmente a vida local e o uso dos espaços públicos - praças, passeios e ruas apontados como a causa da elevada incidência de crimes e vandalismo que invariavelmente acontecem em bairros onde já não existe mais a comunidade tradicional para controlar a vizinhança. Para ela e seus seguidores as intervenções acabam por atrair grandes empresas com alta lucratividade ou cadeias de lojas e supermercados. Desse modo o pequeno comércio tradicional de bairro desaparece, e com ele as relações de atendimento direto. A convivência estabelecida nos espaços públicos, considerado como um dos pilares de sustentação de comunidades locais, também corria riscos de extinção com as obras de expansão de vias urbanas e construção de modernas torres de escritórios e conjuntos habitacionais.
Embora na década de 50, o arquiteto inglês Gordon Cullen, de certa forma continuador de Camilo Sitte revalorizasse a cidade como escala humana, considerando no movimento seqüencial o potencial simbólico que todo o elemento arquitetônico estabelece com o contexto urbano, o arquiteto Kevin Linch, em 1960, desenvolveu uma das mais expressiva contribuição para a analise da cidade e futuras intervenções urbanas..O seu método, de leitura da cidade, originado a partir de pesquisas nas cidades americanas, influenciou, tanto a nível teórico como prático, todos os trabalhos de per- cepção do espaço urbano existentes até os dias de hoje [8].

Continuando na tentativa da valorização do passado, alguns autores caminharam no sentido da ênfase aos estudos morfológicos como metodologia de intervenções urbanas. Tais tratados foram muito utilizados nas intervenções das cidades históricas a partir da década de 70. Assim, em 1965, Rossi publica o livro A Arquitetura da Cidade [9], sendo alguns pontos de destaque desse trabalho, a afirmação de que a cidade é constituída por arquitetura, sendo esta a chave da leitura e a interpretação dos fatos urbanos. Corolário da anterior, que reforça a relação entre a cidade e a arquitetura, a 
crítica ao funcionalismo, na demonstração de que entre a forma $\mathrm{e}$ as funções $\mathrm{e}$ estabelecem relações mais complexas e dialéticas do que as de causa e efeito. Assim, legitima a revalorização das formas urbanas tradicionais - da rua ao quarteirão, da praça ao monumento - bem como da geometria e do traçado, no ato de projetar a cidade. incorporando os monumentos como marcos urbanos e pontos de referência na estrutura urbana.

Todas essas teorias inauguram a partir da década de 60 um novo contexto na teoria urbana de intervenção, o pós-modernismo que assumirá uma postura critica ao modernismo e cultivará para o tecido urbano como algo necessariamente fragmentado. Considerando-o também um palimpsesto de formas superpostas umas às outras e uma colagem de usos correntes, muitos dos quais podem ser efêmero [10]. As opiniões tornam-se mais exigentes, já que implicam que o efeito do entorno construído pode estender-se para alterar as formas de conduta e estimular habitantes urbanos a adotar em novos modelos de ação social.

Na Europa, já na década de 60, os interesses patrimoniais prejudicados pelas tentativas de intervenção planificadoras procuraram resistir. $\mathrm{Na}$ cidade Italiana de Bolonha, as novas medidas adotadas pelo poder público contaram com ampla participação popular e revelavam uma atitude cultural correta, com a tentativa de melhorar as condições da vida urbana, sendo muito utilizadas as idéias de Rossi. [11]. Desde modo, as principais medidas tomadas incluíam a revisão das leis do uso do solo urbano e zoneamento, criação de novos espaços públicos para diminuir o adensamento do núcleo histórico, provendo-o de espaços para instalação das novas redes de infraestrutura e serviços públicos. A questão dos custos da expansão urbana e da especulação com os terrenos nobres localizados nas colinas que rodeiam o núcleo histórico foram consideradas.

O pós-modernismo passa a discutir a noção de preservação, onde se considerava apenas o monumento frente aos resultados muitas vezes caóticos. Como exemplo, pode ser citado a cidade de Ouro Preto, que por pouco não perdeu seu status de patrimônio da humanidade ao ver um núcleo histórico sendo preservado, porém com um entorno sofrendo um forte processo de expansão. Também passa a ser preocupação nas áreas revitalizadas o fortalecimento das atividades culturais locais e o incentivo do uso e-xacta Belo Horizonte
ISSN 1984-3151 www.unibh.br/revistas/exacta

v. 2, n. 1, jun 2069 
habitacional a fim de dinamizar esses espaços [12].

Constata-se que atualmente o processo de intervenção nos centros urbanos torna-se cada vez mais uma estratégia de gestão urbana que procura requalificar a cidade existente através de intervenções múltiplas destinadas a valorizar as potencialidades sociais, econômicas e funcionais, a fim de melhorar a qualidade de vida dos moradores; e atingir objetivos diversos como, por exemplo, o incremento de valor das propriedades; redução de violência; melhor manutenção e utilização dos espaços públicos e dos espaços internos dos prédios; atração de investimentos públicos em infraestrutura urbana; atração de turistas e visitantes; geração de emprego e renda; proteção da integridade dos bairros tradicionais com a respectiva maior apropriação dos processos históricos de construção e urbanização pela população; melhoria da imagem visual das áreas urbanas moldando o imaginário $\quad \mathrm{e} \quad \mathrm{a}$ memória coletiva.

\section{Os paradigmas contemporâneos}

Alguns centros históricos, que estavam sofrendo um processo de degradação físicoespacial, como por exemplo, o Pelourinho em Salvador, voltaram a ter uma melhor qualidade, em razão de programas de revitalização. No Pelourinho a regeneração, dede a década de 90, vem consistindo na limpeza geral, reforma dos casarões (construídos do Século XVI ao XIX) e a atração de atividades comerciais e culturais. Há aproximadamente 15 anos, o centro histórico de Salvador era reduto de marginais e mendigos, que tornavam a área de extremo perigo, principalmente à noite. As intervenções no Pelourinho promoveram a transformação de tal área em um dos principais pontos turísticos da cidade de Salvador.

Com a atuação do IPAC (Instituto do Patrimônio Artístico e Cultural ), o Pelourinho foi ocupado por bares e restaurantes, e morar na região tornou-se signo de status. Rapidamente, casas que antes eram verdadeiros cortiços passaram a valer até dez vezes mais, Segundo uma reportagem " antes da reforma do Pelourinho, uma casa de tamanho médio, com até quatro piso, em estado razoável de conservação, podia ser comprada por 20.000 dólares. Hoje, os casarões maiores e já restaurados valem até dez vezes mais" [13].. Todavia, para algumas pessoas, como AZEVEDO (1994:131), “O novo Pelourinho... limpo, escovado e policiado... 
transformou-se em um cenário. Aquele bairro onde se sentia velha Salvador, aparece hoje como um teatro onde se representa Salvador para turistas” [14]..

Umas das criticas a esse tipo de intervenção é que junto com ela surge um processo de gentrificação. O termo "gentrification" foi usado por volta de 1964 para descrever um fenômeno que estava ocorrendo na cidade de Londres. Parte da classe média estava trocando os subúrbios pelo centro, enquanto que os antigos moradores estavam sendo paulatinamente expulsos dos bairros mais degradados os quais estavam recebendo maior investimento de entidades públicas e privadas. [15].

Outras propostas de revitalizações urbanas em áreas degradadas têm sido realizadas em grandes cidades, o projeto Rio Cidade realizado pela Prefeitura do Rio de Janeiro. “ ... surgiu a partir da constatação da necessidade de "requalificação" $e$ disciplinamento dos espaços públicos, combatendo seu uso ilegal, reconstruindo e restaurando ruas e praças, apostando em sua qualificação por meio de propostas de alto padrão técnico e estético [16].

Estimulado, no entanto, pelo crescimento do período conhecido como "milagre econômico", ainda nas décadas 1960 e 1970, o centro do Rio de Janeiro acompanhou um movimento de intensa verticalização, ocorrido principalmente em alguns daqueles bairros que abrigavam as novas centralidades. Na década de 1980, com na maioria das grandes cidades brasileiras, acentuou-se este processo de esvaziamento do centro do Rio de Janeiro, quando, em função da concorrência representada pelos novos sub-centros e mesmo por outras cidades, várias empresas de grande porte deixaram a área. Os investimentos, públicos e privados, no Centro diminuíram e a decadência dos espaços físicos e das edificações passou a refletir ta situação. Diante deste quadro, o poder público, nos anos 90, inicia uma serie de intervenções a fim de remediar toda essa problemática surgida.

A metodologia utilizada no Rio para as intervenções foi a definição das prioridades pela Prefeitura - as equipes responsáveis pelos projetos elaboraram os diagnósticos e depois os projetos, os quais foram encaminhados, então, para debate na comunidade e transformados em obra. Uma das intervenções concretizadas consistiu na reformulação do eixo viário, histórico e comercial, constituído pela Rua do Catete. 
Assim, foram introduzidas modificações no traçado da rua e das calçadas, bem como a criação de praças, o tratamento de espaços degradados, além da criação de jardins, da implantação de um novo mobiliário urbano e da sinalização. "O objetivo proposto foi o de reativar setores dos bairros, concebendo o espaço público como lugar de encontro, de trocas, visto principalmente do ponto de vista do pedestre, ao mesmo tempo em que disciplina e limita a presença do automóvel" [17]. Embora o Bairro do Catete seja uma área de forte referencial histórico do Rio de Janeiro, o projeto não implicou, necessariamente, a busca da reconstituição do passado. Seguindo a filosofia dos projetos da última década, “nestes projetos, a função da imagem é de máxima relevância para gerar focos de identidade capazes de galvanizar o imaginário coletivo, singularizando cada intervenção” [18].

Hoje, na Rua do Catete, transcorridos aproximadamente dez anos das primeiras modificações, pode-se constatar, por meio da vistoria in locu e das entrevistas com os freqüentadores do bairro, que, embora as intervenções não tenham tido continuidade, as modificações realizadas trouxeram nova vitalidade à região, com a conseqüente revitalização do seu comércio. A ampla aceitação do processo de intervenção do Centro e as conquistas por ele alcançadas deram impulso a várias outras iniciativas nos espaços degradados na zona periférica do centro e portuária [19].

$\mathrm{Na}$ esfera internacional, Barcelona tem sido, desde Olimpíada de 1992 até hoje um importante centro de arquitetura e urbanismo. A cidade pode ser considerada exemplo da aplicação de profundas intervenções urbanas. As principais intervenções ocorreram sob a direção do arquiteto, crítico e professor Bohigas [20].

No projeto de BOHIGAS, sentem-se as lições de Lynch [21] tais como a preocupação com pontos de referência e algo das teorias das tipologias de Rossi. A experiência urbanística da cidade baseou-se nos seguintes critérios: reconstrução da cidade existente; consideração da urbe, não como um sistema total, senão como justaposição de elementos focalizados nos bairros; legibilidade apoiada em “morfologias tradicionais - como conteúdo iniludivel de uma identidade e uma coesão social” [22], estruturação dos fluxos viários; atuação pontual em áreas estratégicas; prioridade do projeto de espaços públicos; utilização de planos setoriais e temáticos. e-xacta Belo Horizonte
ISSN 1984-3151 www.unibh.br/revistas/exacta

v. 2, n. 1, jun 21089 
Para Bohigas [23] "toda essa atuação urbanística é fundamentalmente proporsitiva e promocional”. Já Buchanam [24], diretor de The Architectural Review, "nenhuma outra cidade tem sido acometida deliberadamente por uma regeneração completa e global como Barcelona" (1992:37). Todos os bairros foram afetados e a intervenção vem ocorrendo desde o mobiliário até os interiores das lojas e bares. Nos projetos da Vila Olímpica em Nova Icária, antiga área formada por velhos galpões industriais, atuaram arquitetos de renome internacional, tais como Álvaro Siza, Bofill e Frank Gehry.

Barcelona atrai, hoje, além de turistas de todo o mundo, empresas de design e de pesquisa tecnológica. Para muitos, como se apresenta hoje, Barcelona "não lembra em nada a cidade decadente de vinte anos atrás, que estava sendo abandonada. $O$ segredo da virada foi uma aplicação de recursos na recuperação de ruas e praças e em telecomunicações" [25]. O diferencial de Barcelona para a escolha por parte de grandes empresas que têm procurado a cidade para ali se instalarem é " $a$ tranqüilidade, a certeza de que se pode passear à noite pelas ruas num ambiente agradável, repleto de árvores e com bares e restaurantes de qualidade, sem risco... $e$ hoje as pessoas querem conforto, praticidade e segurança” [26].

\section{Considerações finais}

Nos projetos urbanísticos aqui apresentados, constata-se a importância dada às qualidades arquitetônicas e urbanísticas para a revitalização das áreas urbanas, não se desconsiderando as questões sociais, econômicas, entre outras. Em todas, o tratamento dos elementos arquiteturais foi fundamental para a recriação de um novo ambiente. Em muitas das propostas aqui analisadas utilizaram-se as metodologias relacionadas à imagem e aos aspectos estéticos de Lynch e Cullen.

Porém, verifica-se que muitas dessas intervenções tendem a se tornarem uma verdadeira "panacéia", contando com grandes recursos publicitários [27]. Todos os esforços não deixam de criar uma encenação de uma vida pública desaparecida há muito tempo. A Arquitetura Pós-modernista - ao procurar resgatar os espaços públicos das cidades e, reconstruílos à maneira da arte cívica herdeira de Sitte acaba por favorecer a proliferação de projetos pontuais, fragmentários e operações de embelezamento. 
A intervenção nos centros urbanos, hoje, é uma atividade cada vez mais presente em nossas cidades. Ao observar os processos de revitalização urbana na Europa, em Barcelona, ou de Bilbao, ou as de Shanghai e Osaka dos últimos 15 anos, e os do Brasil - Pelourinho e Rio- Cidade, conclui-se que o espírito empreendedor do poder público que, ao mobilizar o apoio popular e a confiança de investidores privados, conseguiu conceber e pôr em execução complexos planos de ação estratégica de reabilitação urbana.

A grandiosidade e a originalidade de concepção da arquitetura em alguns desses centros urbanos concebidos com a mais avançada engenharia e sofisticados materiais de construção, e o cuidadoso desenho urbano em outros, tiveram por objetivo criar o novo marco visual, lançando a imagem das cidades a nível global.

Apesar de muitos críticos considerem que tais propostas tornem as respectivas áreas revitalizadas semelhantes a museus, não há como negar que as intervenções proporcionaram uma melhoria ambiental a essas áreas embora pese o seu respectivo embelezamento.
Percebe-se que atualmente, existe uma tendência de uniformização cultural, o que vem gerando, nos centros das cidades, uma padronização até mesmo em termos de materiais como o aço inox, as calçadas coloridas, e uma arquitetura de grandes prédios "espelhados", símbolo da tecnologia e padrão das grandes cidades que se dizem modernas.

Essa perda da diversidade, a que Jacobs [28] atribuía tanta importância, produz reflexos sobre a qualidade de vida das pessoas.

Contudo, a esses trabalhos denominados de maquiagem urbana, poder-se-ia agregar outros, com uma abordagem mais abrangente, no nível arquitetural, a qual garanta uma maior habitabilidade a esses espaços e, conseqüentemente, a redução dos conflitos arquitetônicos entre os usuários (não só os turistas, como os próprios moradores) e o espaço. Para isso, faz-se necessário, também, utilizar metodologias que não se baseiem apenas em aspectos visuais, mas que se apóiem em bases comportamentais, ampliando os resultados das propostas de revitalização. e-xacta Belo Horizonte
ISSN 1984-3151 v. 2, n. 1, jun æ09 
A prática atual de intervenção urbana devese preocupar com ações de reimplantação de antigas funções urbanas, como habitação, comércio, serviços e cultura. Abranger, também a readequação do patrimônio cultural existente - como aconteceu no Pelourinho - bem como o incremento do turismo e do lazer e a preocupação com as possibilidades de potencialização dos espaços físicos, em torno de uma padronização mundial.

O conceito atual de intervenção urbana, denominado de reabilitação ou requalificação, portanto, está menos ligado à idéia de perda de vitalidade e traz mais clara a idéia de acréscimo de atividades geradoras de ganhos econômicos e de melhoria da qualidade dos espaços públicos e privados, podendo ser melhor aplicado em situações onde se trata de alteração das características físicas e da composição social e econômica de áreas ainda ocupadas.

Hoje, cada vez mais o financiamento das intervenções originam de várias fontes, com substantivas dotações provenientes das empresas públicas, setor privado, e das fundações, despertando crescente interesse da sociedade civil, comunidades locais e da diversidade de seus grupos sociais e étnicos, das organizações comunitárias e das ONGs.
Verifica-se ainda um crescente papel exercido pelos movimentos sociais urbanos, contrapondo-se aos interesses imobiliários, na luta pela proteção de conjuntos históricos urbanos, estruturas e sítios sagrados, ou de áreas naturais de conservação.

A esse movimento de preservação de patrimônio histórico e cultural se juntam movimentos de preservação da natureza, sobretudo na idéia da sustentabilidade, ou seja, na preocupação em proteger e passar o patrimônio herdado dos antepassados, para as futuras gerações.

Duas tarefas tornam-se fundamentais nesse processo de reabilitação de centros urbanos históricos: primeiro a necessidade de uma abordagem de planejamento que contemple os diversos atores envolvidos; e segundo na gestão participativa, adotando uma abordagem multidisciplinar, na qual todos os atores, como por exemplo, os gestores públicos, os investidores privados e o cidadão comum, participem nas deliberações e estejam afins com as decisões tomadas contidas nos programas de reabilitação.

Nesse contexto, a participação da população deve-se tornar um exercício 
continuado, desde a esfera inicial até o final das intervenções, pois na medida em que o processo caminha, novas tendências vão aparecendo nas pautas de deliberações, podendo impactar as decisões e até influenciar o câmbio de prioridades políticas. Essa continuidade é a base institucional sólida sobre a qual se deve apoiar boa parte da prática de gestão. Cabe então aos gestores públicos facilitar tal participação e a formação de parcerias estratégicas, negociando os detalhes de financiamento para assegurar a realização do empreendimento [29].

Evita-se com isso a perda da eficácia com relação a outros conflitos arquitetônicos, resultantes das interações entre as pessoas e o espaço; que tendem a serem camuflados, e, por isso, as propostas deixam a desejar com relação ao aspecto de oferecer um espaço urbano, com equipamentos adequados e qualidades que favoreçam a sua habitabilidade plena.

Embora pese as tentativas ao contrário, constata-se que a requalificação voltada para o estabelecimento de novos padrões de organização e utilização dos espaços, envolvendo processos de elitização e gentrificação, com vistas a um melhor desempenho econômico acaba por favorecer que o patrimônio cultural assuma valor de mercadoria. Porém, constata-se que na trans-formação do patrimônio cultural áreas reabilitadas em mercadoria estabelece-se uma possibilidade da inserção global para cidades que não possuem outras características ou posicionamentos estratégicos num mundo globalizado. Entretando é fundamental atentar para os enflamados discursos de revitalização que muitas vezes escondem uma faceta gentrificadora pouco voltada para a população e sim pelos interesses de mercado.

\section{Referências bibliográficas}

[1] BENEVOLO, Leonardo. História da cidade. São Paulo: Editora Perspectiva, 2002.

[2] BROADBENT, Geoffrey. Emerging concepts in urban space design. New York: Van Nostrand Reinhold, 1999.

[3] SITTE, Camilo. A construção das cidades, segundo seus Princípios Artísticos. São Paulo: Editora Ática, 1992.

[4] LAMAS, José M Ressano Garcia.. Morfologia urbana e desenho da cidade. Lisboa: Fundação Calouste Gulbenkian, 2000, p.244.

[5] Id., ibid., p.303. 
[6] ARANTES, Otília Beatriz Fiori. $O$ lugar da arquitetura depois dos modernos. São Paulo: Editora Universidade de São Paulo, 1995, p.113.

[7] JACOBS, Jane. Muerte y vidas de Ias grandes ciudades norte-americanas. Madrid: Ed. Península, 2005.

[8] CULLEN, Gordon. A Paisagem urbana. Lisboa: Edições 70, 1983.

[9] ROSSI, Aldo. La Arquitectura de la ciudad. Barcelona: Gustavo Gilli, 1982.

[10] HARVEY, David. Condição pósmoderna. São Paulo: Edições Loyola, 2004. [11] EPHIM, Shluger,. A Revitalização de Áreas Urbanas: Curso de Gestão. Escola de Governo da Fundação João Pinheiro, 2001 [12] VARGAS, Heliana Comin. Intervenções em Centros Urbanos: objetivos, estratégias e resuldos. Baueri, SP: Manole, 2006.

[13] SETTI, Adriana. Pelourinho. Veja, São Paulo, nº 30, 28 julho 1999, p.78.

[14] AZEVEDO, Roberto Marinho. Será o novo Pelourinho um engano? Revista do Patrimônio Histórico e Artístico Nacional, Rio de Janeiro, p.130-5, 1994.

[15] ZUKIN, Sharon. Gentrification:

Culture and Capital in the Urban Core.
Annual Review of Sociology, Vol. 13, 1987.

[16] ZEIN, Ruth Verde. Urbanismo Rio : intervenções pontuais. Projeto/Design . São Paulo: Editorial Arco, nº 201, out. 1996, p.42.

[17] Id., ibid., p.43.

[18] Id., ibid., p.47.

[19] MAGALHÃES, Roberto Anderson M. Preservação e requalificação no Centro do Rio de Janeiro nas décadas de 1980 a 1990. Universidade Estadual de Ourinhos. São Paulo,2002

[20] BOHIGAS, Oriol. Una nueva Barcelona. Reflexiones sobre os últimos diez anos. $A \& V$, Madrid, no 37 , out. 1992 , p.6.

[21] LYNCH, Kevin. A imagem da cidade. São Paulo: Martins Fontes, 1985.

[22] BOHIGAS, Oriol. Op. Cit, p.7.

[23] Id., ibid., p.11.

[24] BUCHANAM, Peter. Modernidad con memória. $A \& V$, Madrid, $\mathrm{n}^{\circ} 37$ out. 1992, p.37.

[28] JACOBS, Jane. Op. Cit, 2005.

[29] EPHIM, Shluger. Op. Cit. 2001. e-xacta Belo Horizonte
ISSN 1984-3151 v. 2, n. 1, jun ख्खB 9 